\title{
Superior mesenteric artery syndrome in a young woman
}

\section{Carlos Andre Barroso Oliveira, ${ }^{1}$ Luciana Barbosa, ${ }^{2}$ Teresa Dionísio ${ }^{3}$}

${ }^{1}$ Hospital de Braga, Fafe, Portugal

${ }^{2}$ Hospital de Braga, Braga Portugal

${ }^{3}$ Department of Radiology, Hospital de Braga, Braga, Portugal

\section{Correspondence to}

Dr Carlos Andre Barroso Oliveira,

carlosaboliveira2014@gmail. com

Accepted 21 February 2017

CrossMark

To cite: Oliveira $C A B$, Barbosa L, Dionísio T. BMJ Case Rep Published online: [please include Day Month Year] doi:10.1136/bcr-2017219421

\section{DESCRIPTION}

Vascular structures in the abdomen and pelvis can be compressed by anatomical structures or cause the compression of adjacent hollow viscera. Superior mesenteric artery syndrome (SMAS) consists of obstruction of the third portion of the duodenum due to compression between the superior mesenteric artery (SMA) and the aorta. ${ }^{1}$ The SMA typically arises at the L1-L2 level with an anterior and inferior course, and the third portion of the duodenum crosses between the aorta and the SMA at L3. The normal aorto-mesenteric angle (AMA) and aorto-mesenteric distance (AMD) are considered to be $28^{\circ}-65^{\circ}$ and $10-34 \mathrm{~mm},{ }^{23}$ respectively. Our images demonstrate the classic findings of

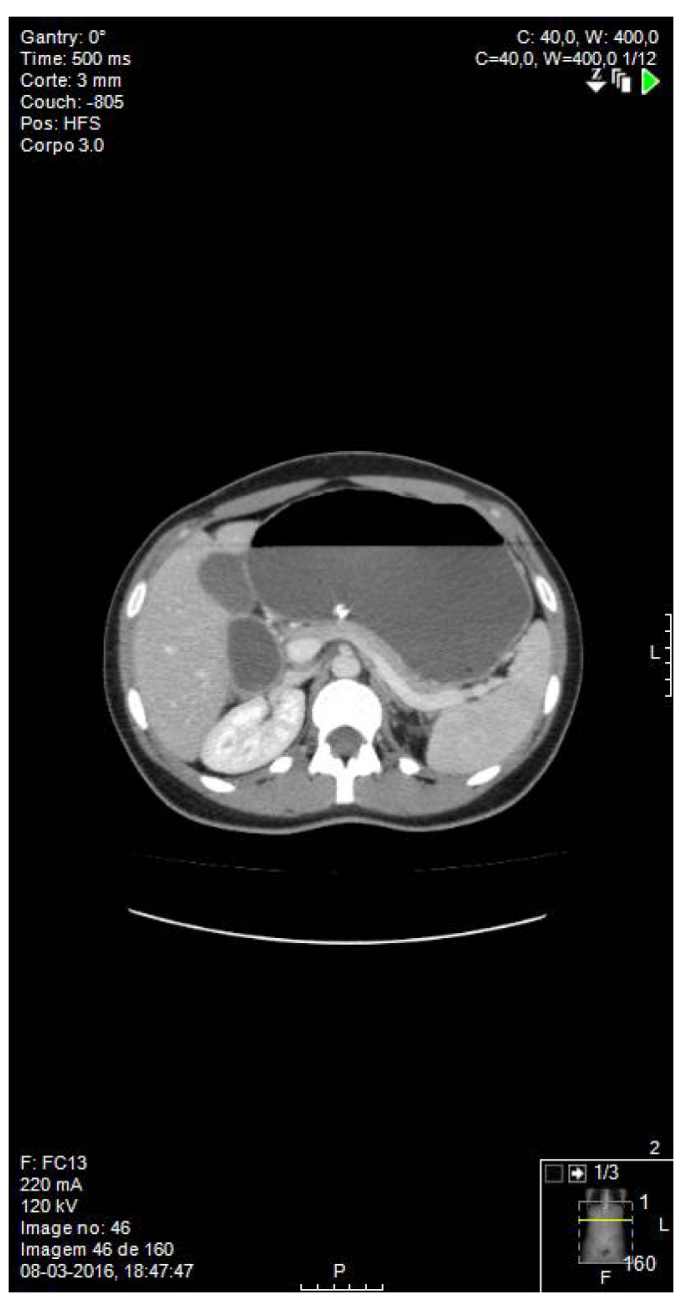

Figure 1 Axial-obstruction of the third portion of the duodenum between the superior mesenteric artery and the aorta with an abrupt cut-off.
SMAS in a woman aged 31 years experiencing rapid weight loss with epigastric pain and fullness, showing the CT duodenal obstruction with an abrupt cut-off in the third portion (figure 1), abnormally low origin of the SMA (figure 2) with an AMA of $10^{\circ}$ and an AMD (the most specific sign) of $7 \mathrm{~mm}$ (figure 3), and the importance of sagittal imaging to the measurements (figure 3 ). We also demonstrate one of the classic signs in ultrasound scan, stomach fullness, despite the inability to identify the AMA (figure 4).

As the presentation was acute, treatment was conservative and consisted of nasojejunal feeding to bypass the obstructions, small liquid meals and mobilisation of the patient. She was discharged

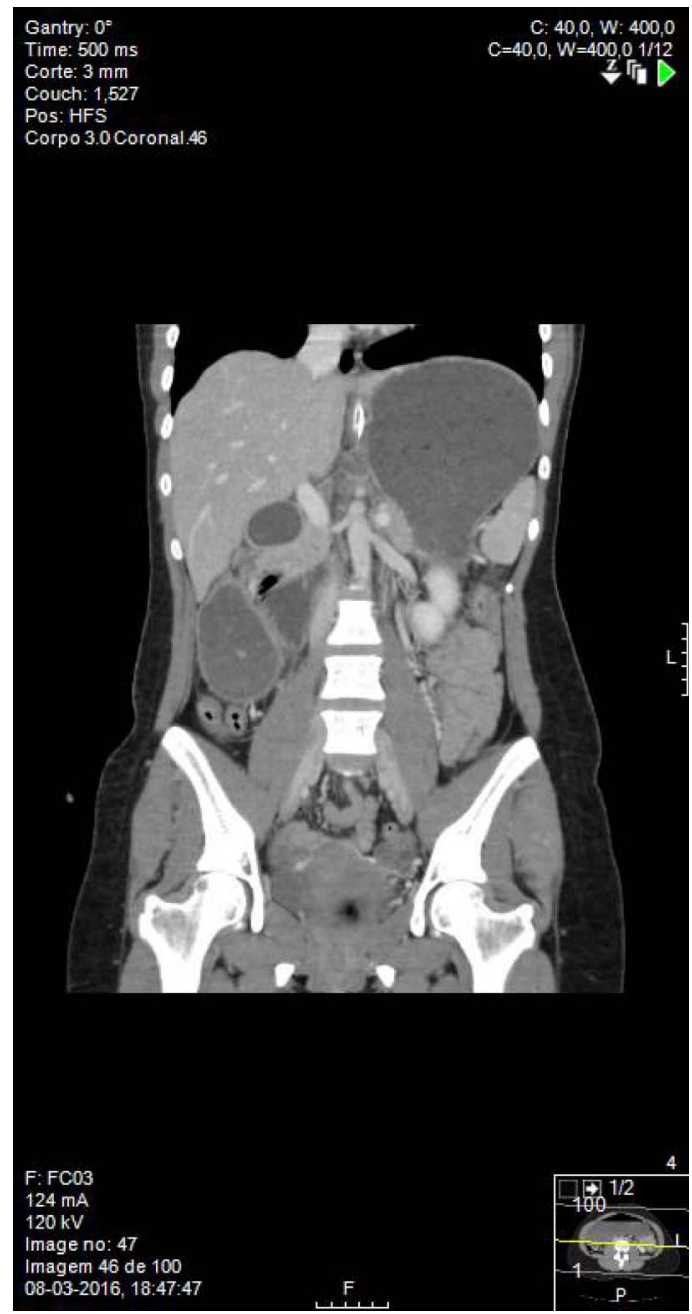

Figure 2 Coronal-duodenal obstruction with an abrupt cut-off in the third portion, abnormally low origin of the superior mesenteric artery. 
Figure 3 Sagittal—abnormally low origin of the superior mesenteric artery with an aorto-mesenteric angle of $10^{\circ}$ and an aorto-mesenteric distance of $7 \mathrm{~mm}$.
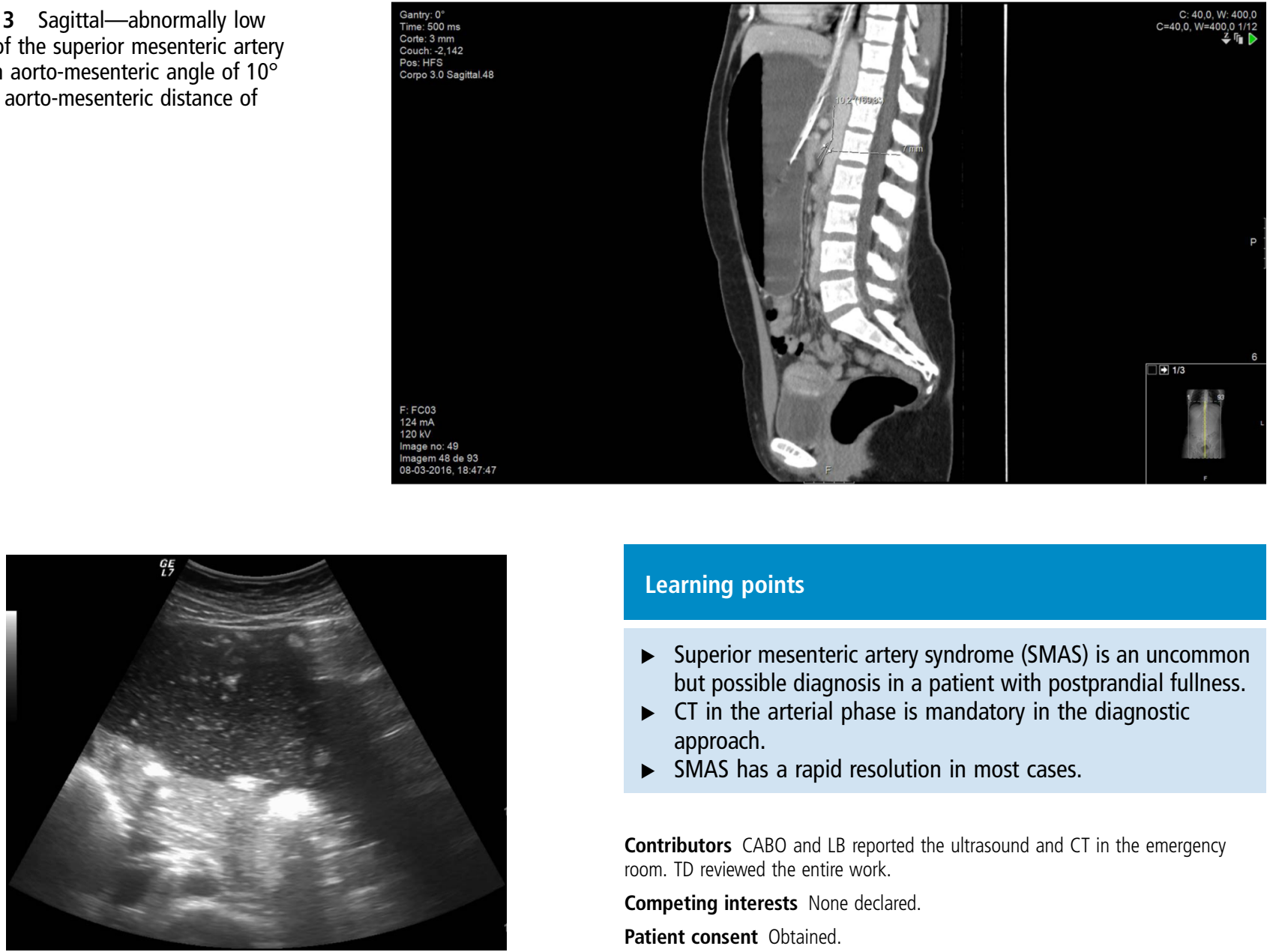

Learning points

- Superior mesenteric artery syndrome (SMAS) is an uncommon but possible diagnosis in a patient with postprandial fullness.

- $\mathrm{CT}$ in the arterial phase is mandatory in the diagnostic approach.

- SMAS has a rapid resolution in most cases.

Contributors $C A B O$ and $L B$ reported the ultrasound and $C T$ in the emergency room. TD reviewed the entire work.

Competing interests None declared.

Patient consent Obtained.

Provenance and peer review Not commissioned; externally peer reviewed.

\section{REFERENCES}

1 Ghaye B, Remy J, Remy-Jardin M. Non-traumatic thoracic emergencies: CT diagnosis of acute pulmonary embolism diagnosis II. Semin Nucl Med 2002;32:173-82.

2 Washington L, Goodman LR, Gonyo MB. CT for thromboembolic disease. Radiol Clin North Am 2002;40:751-71.

3 Wu AS, Pezzulo JA, Cornan JJ, et al. CT pulmonary angiography: quantification of pulmonary embolism: prospective detection on routine helical CT scans. Radiology 1998;208:209-15 changes.

Copyright 2017 BMJ Publishing Group. All rights reserved. For permission to reuse any of this content visit http://group.bmi.com/group/rights-licensing/permissions.

BMJ Case Report Fellows may re-use this article for personal use and teaching without any further permission.

Become a Fellow of BMJ Case Reports today and you can:

- Submit as many cases as you like

- Enjoy fast sympathetic peer review and rapid publication of accepted articles

- Access all the published articles

- Re-use any of the published material for personal use and teaching without further permission

For information on Institutional Fellowships contact consortiasales@bmjgroup.com

Visit casereports.bmj.com for more articles like this and to become a Fellow 